\title{
Development and Validation of Corona Virus Anxiety Scale (CVAS)
}

\author{
Afreen FAIZA \\ Research Associate, Ilma University (Formerly Institute of Business \& Technology), Karachi, Pakistan
}

(Corresponding author's e-mail: afreenfaiza2014@gmail.com)

Received: 16 April 2020, Revised: 8 July 2020, Accepted: 15 July 2020

\begin{abstract}
Background and Objectives: The advent of 2020 was eclipsed by an epidemic crisis of COVID-19. The swift spread of fatal viruses creates paralyzing apprehensions among all human beings and has produced a need to develop a sound psychometric scale to measure anxiety related to COVID-19.

Methods: Items for a Corona Virus Anxiety Scale (CVAS) emerged from literature reviews, a SARS fear scale, and qualitative analysis of interviews. After successive item modifications and pilot-testing, the 17-item self-reported CVAS was administered to $(\mathrm{N}=256)$ participants. A sample of $(\mathrm{N}=45)$ individuals was recruited for determination of CVAS construct validity with the Impact of Event ScaleRevised (IES-R).

Results: Exploratory factor analysis (EFA) showed 3 factors with $57.46 \%$ variance, Fear of Infection and Death (FOIAD), Social Isolation (SI), and Loss of Control and Helplessness (LOCAH). Item-total correlation values ranged from $(\mathrm{r}=0.46$ to $0.63, p<0.01)$. Overall, CVAS showed a highvalue Cronbach alpha reliability $(\alpha=0.896)$; alpha reliabilities for subscales also lay in acceptable ranges. The relationship between CVAS and IES-R suggests significant and positive correlation values $(\mathrm{r}=$ $0.477, * * p<0.01$ ), demonstrating the construct validity of the newly-developed CVAS.

Interpretation and Conclusions: CVAS is a reliable and valid self-reporting tool for screening of anxieties about COVID-19 among the general population.
\end{abstract}

Keywords: Coronavirus Anxiety Scale (CVAS), Development, Reliability, Validity, Self-report

\section{Introduction}

Presently, the globe has been jolted by coronavirus (COVID-19), which is the third viral disaster after SARS-CoV [1] spread in 2002 and MERS in 2012 [2]. It has adversely impacted all spheres of life so much that the World Health Organization (WHO) announced the emergence of COVID-19 as a public health crisis that warrants international attention [3]. COVID-19 was initially recognized in late 2019 after a report of clinical incidences featuring pneumonia-like symptoms, presumably linked with an open seafood market located in Wuhan, China [4]. Since then, the dreadful virus has been rapidly transmitted via human to human interactions from Wuhan to other cities of China, Asia, and all over the world [5].

Worldwide epidemic spread of COVID-19 is a fearful condition that demands suitable attention related to the psychological health of people for societal benefits [6]. Previous studies carried out during outbreaks of epidemic influenza suggest negative psychological effects on individuals. Research conducted in the initial period of the SARS outburst reported anxiety, panic attacks, prolonged depression, psychosis, delirium, and suicide [7,8]. Individuals reported fear of being sick, dying, helplessness, and stigma [9]. Epidemic viral outbreaks induce a cluster of anxieties among people, ranging from the chance of being infected by virus [10], shutting down of business and educational institutes, and a mixture of complex negative emotions [11].

Similarly, over the past decade, epidemic spreads of strands of coronavirus analogous with present COVID-19 has jeopardized psychological health and induced anxiety and fears among people. The robust 
http://wjst.wu.ac.th

global spread of COVID-19 has created a dire need to organize health care structures and warn common people to stay alert in terms of medical and mental health [12]. To date, little is known about the psychological impacts on individuals following the outbreak of COVID-19.

To our best knowledge, there is a paucity of scales that have been developed to comprehensively address multifaceted anxieties and fears related to the epidemic spread of COVID-19, except for a recent Coronavirus Anxiety Scale (CAS) which is a short and single anxiety construct with a narrow focus on somatic complaints of anxiety (dizziness, sleep disturbances, tonic immobility, appetite loss, abdominal distress). Scorings of CAS are based on DSM-5 adult rating symptom measurements, utilized as a mental health screening tool for dysfunctional anxiety liked with COVID-19 [13]. The presently-designed Corona Virus Anxiety Scale (CVAS) is a multi-dimensional construct aiming to measure anxiety related with COVID-19 based on experiences of the general population. However, the screening properties of the CVAS to measure psychiatric symptoms and anxiety disorders over time and response to treatment is yet to be established following the criterion of DSM-5 considering clinical and non- clinical population.

The present paper is an effort to develop and validate the CVAS to measure anxiety and related fears among the general public. The study aspires to contribute an empirically sound measurement tool for usage in future studies to investigate anxieties and fears related to COVID-19.

\section{Material and methods}

\section{Development of Corona Virus Anxiety Scale (CVAS)}

The study aimed to construct and validate a scale to measure anxieties related to the novel coronavirus. Data was collected from $15^{\text {th }}$ March $-29^{\text {th }}$ March 2020 during the outbreak of the epidemic eruption of COVID-19 in Pakistan. The first reported incidence was in February 26th, 2020, which climbed to 1,856 affirmed cases, along with 25 deaths, to March 2020 [14]. Pakistan is an underdeveloped region; data collected during viral upsurge is assumed to describe the greatest impact, as researches have documented that developing countries possess an augmented level of fear about an epidemic more than an epidemic itself [15-17].

\section{Item development}

The following sources provided an outline to develop a preliminary item pool: a literature review based on short communications, news reports, and journal articles about anxieties related to coronavirus provided ideas about related domains for item development. An 18-item SARS Fear Scale (SFS) [18] with 3 distinct factors (infection, insecurity, and instability) represents multidimensional fears during the peak of the SARS outbreak. SFS was a tool designed during the initial peak of the SARS outbreak in Hong Kong, based on the experiences of hospital staff providing counseling services to health care professionals engaged in the care of patients infected with SARS. Reviews concerning item content, response categories, and components present in SFS [18] provided a framework to develop an initial pool of items for the CVAS.

Online interviews with the general population regarding their concerns and fears related to COVID19 also aided the development of items. The following open-ended questions were used with key informants: What do you understand about coronavirus anxiety or fears related to coronavirus? What are the main reasons for corona related anxiety/fear among the general public? What are the thoughts and emotions that come to your mind when someone speaks to you about the coronavirus? Approximately 20 interviews were qualitatively analyzed. Based on 3 sources, general and specific themes for item development of the CVAS were identified: Fear of Infection and Death (FOAID), Social Isolation (SI), and Loss of Control and Helplessness (LOCAH). 20 items were written based on 3 components. A 4point Likert scale (Strongly agree $=4$ to Strongly Disagree $=1$ ) was assigned to record responses. The items were given to 3 subject experts for the sake of content specificity and face validity; their suggestions were incorporated to modify the wording and enhance the clarity of items. 
http://wjst.wu.ac.th

\section{Pilot study}

Items were administered to 20 individuals ( 10 men, 10 women), aged 18 - 46 years. 3 items were discarded because of their ambiguity and lack of clarity. The final set of items was again given to 3 subject experts for further refinement in terms of clarity and aptness. All items were positively worded.

\section{Study sample}

The sample included 1:10 item per response. 256 individuals (105 men \& 151 women) with ages ranging from 18 - 46 years were recruited for scale development and psychometric analysis. Participants were recruited through a random sampling method in which every individual in a population possessed an equal opportunity for participation $[19,20]$. Inclusion criteria for participants included the absence of past or present psychological/physical disease, an ability to comprehend English with minimal anticipation, and age brackets ranging from 18 - 46 years. 45 individuals ( 21 men \& 20 women), ages ranging from 18 - 46 years, were taken for validation of CVAS.

\section{Instruments}

An Impact of Event Scale-Revised (IES-R) short 22-item scale with 3 subscales (intrusion, avoidance, and hyperarousal) designed to measure psychological effects after recent exposure of traumatic events within 7 days interval was used. Overall and subscales of the IES-R demonstrated acceptable alpha reliabilities; subscale intrusion values ranged from $0.87-0.91$, subscale avoidance from $0.84-0.85$, and subscale hyperarousal from $0.79-0.9$ [21].

The SARS Fear Scale (SFS) was somewhat similar to the CVAS, showing a positive relationship with post-traumatic stress symptoms measured by IES-R among health care workers [22], providing empirical grounds to include IES-R in the present study to investigate the construct validity of the CVAS. Also, the IES-R recommended accessing recent traumatic incidents, everyday distresses, and the effect of daily life stress [21]. It has been utilized to estimate psychological responses due to stressors like diseases $[23,24]$ and injuries $[25,26]$. levels.

A personal information sheet included demographic details about age, gender, and educational

CVAS: A brief scale included 17 items dispersed in 3 subscales. Response categories for a 4-point Likert scale ranged from (strongly agree $=4$, strongly disagree $=1$ ). Scores ranged from $1-68$; higher scores showed greater levels of COVID-19 anxiety.

\section{Procedure}

Data was collected through an online Google form drafted in English. An online link to the questionnaire was posted on different social networking sites (Facebook, Twitter, Instagram, and WhatsApp groups), with an invitation for voluntary participation; individuals were eligible to access information only if they provided consent for participation. Data was gathered over a short period of 15 days. Statistical analysis was done by using SPSS 22 (SPSS Inc., Chicago, III., USA), including corrected item-total correlations and Cronbach's alpha for item analysis and reliability, Pearson's correlation coefficients for construct validity, and factor analysis (EFA) for dimension reduction of the CVAS.

\section{Results}

Factor analysis

Exploratory Factor Analysis (EFA) showed a Pearson correlation matrix for 17 items of the CVAS. The value of Kaiser-Meyer-Olkin Measure of Sampling Adequacy (KMO) 0.852 indicated matrix suitability of run factor analysis. Bartlett's Test of Sphericity $(\chi 2=2183.10, p<0.001)$ suggested positive correlations for variables. 
http://wjst.wu.ac.th

Table 1 Item loadings, Eigen Values, and common variance explained after orthogonal rotation.

\begin{tabular}{llcc}
\hline Items & FOAID & SI & LOCAH \\
\hline 1 & 0.788 & & \\
2 & 0.869 & & \\
3 & 0.771 & & 0.511 \\
4 & & \\
5 & 0.439 & & 0.469 \\
6 & & & 0.690 \\
7 & & & 0.661 \\
8 & & 0.521 & \\
9 & & & 0.523 \\
10 & 0.561 & & \\
11 & 0.689 & 0.813 & \\
12 & & 0.778 & \\
13 & & 0.819 & 1.29 \\
14 & & 0.746 & 7.61 \\
15 & 6.47 & 1.99 & 57.46 \\
16 & 38.10 & 11.75 & \\
17 & & 49.85 & \\
Eigen Values & & \\
Percentage Variance & & \\
Cumulative Percentage & 38.10 & & \\
\hline Note: FOIAD $=$ Fear of Infection and Death; SI $=$ Social Isolation; LOCAH $=$ Loss of Control and \\
Helplessness ** $<0.01$ & &
\end{tabular}

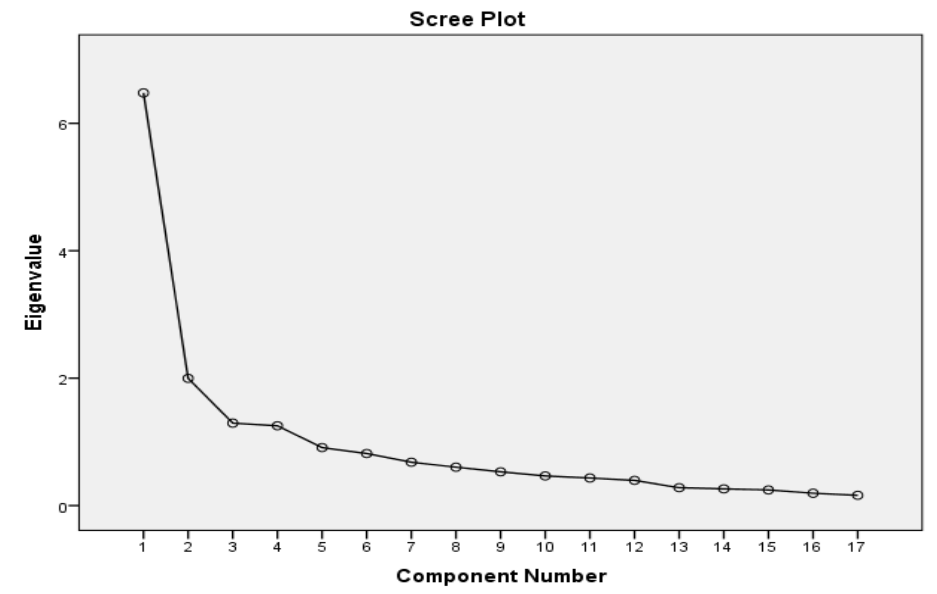

Figure 1 Scree plot.

Table 1 shows that Principal Component Analysis (PCA) with Varimax Rotation suggests a 3 factors solution provided the best fit with refined structure and was linked with expected dimensions of the CVAS. Items for 3 factors showed $57.46 \%$ of the variance. The Scree plot (Figure 1) showed a sharp decline after 3 factors, indicating retention of 3 factors for the CVAS, interpreted as Fear of Infection and Death, Social Isolation, and Loss of Control and Helplessness. 
http://wjst.wu.ac.th

Item and scale analyses

Table 2 shows means, standard deviations, and item-total correlation values of CVAS. Maximum and minimum discrimination indices for items in overall CVAS ranged from 0.46 to 0.63 .

Table 2 Descriptive statistics and item-total correlation CVAS.

\begin{tabular}{llll}
\hline Items & Mean & Standard deviation & Item-total correlation \\
\hline 1 & 2.9 & 0.74 & 0.62 \\
2 & 3.1 & 0.73 & 0.58 \\
3 & 3.1 & 0.81 & 0.55 \\
4 & 3.2 & 0.79 & 0.56 \\
5 & 2.7 & 0.79 & 0.49 \\
6 & 2.9 & 0.80 & 0.53 \\
7 & 3.2 & 0.79 & 0.51 \\
8 & 3.1 & 0.75 & 0.46 \\
9 & 3.0 & 0.83 & 0.50 \\
10 & 2.7 & 0.95 & 0.50 \\
11 & 2.7 & 0.93 & 0.52 \\
12 & 2.3 & 0.88 & 0.62 \\
13 & 2.9 & 0.88 & 0.49 \\
14 & 2.6 & 0.89 & 0.61 \\
15 & 2.5 & 0.88 & 0.62 \\
16 & 2.8 & 0.90 & 0.54 \\
17 & 2.7 & 0.90 & 0.63 \\
\hline$* * p<0.01$ & & &
\end{tabular}

Table 3 Descriptive Statistics, Item-total Correlation, and Alpha Reliability cut-off scores of CVAS and subscales.

\begin{tabular}{lllllllll}
\hline Scales & $\begin{array}{l}\text { Item-Total } \\
\text { correlation } \\
\text { maximum }\end{array}$ & $\begin{array}{l}\text { Item-Total } \\
\text { correlation } \\
\text { minimum }\end{array}$ & $\begin{array}{l}\text { Alpha } \\
\text { reliability }\end{array}$ & Mean & $\begin{array}{l}\text { Standard } \\
\text { deviation }\end{array}$ & $\begin{array}{l}\text { Percentile } \\
\mathbf{7 5}^{\text {th }} \\
\text { High } \\
\text { scores }\end{array}$ & $\begin{array}{l}\text { Percentile } \\
\mathbf{5 0}^{\text {th }} \\
\text { Medium } \\
\text { scores }\end{array}$ & $\begin{array}{l}\text { Percentile } \\
\mathbf{2 5}^{\text {th }} \\
\text { Low } \\
\text { scores }\end{array}$ \\
\hline FOIAD & 0.75 & 0.44 & 0.844 & 17.0 & 3.6 & 19 & 17 & 15 \\
SI & 0.75 & 0.42 & 0.845 & 13.4 & 3.5 & 16 & 14 & 11 \\
LOCAH & 0.56 & 0.38 & 0.759 & 18.2 & 3.3 & 21 & 18 & 16 \\
CVAS & 0.63 & 0.46 & 0.896 & 48.6 & 8.8 & 54 & 49 & 43 \\
\hline
\end{tabular}

Table 3 shows item-total correlation values for subscales ranging from 0.75 - 0.38 . Alpha reliabilities for overall CVAS and subscales lie in acceptable ranges. Means and standard deviations and cut-offs for total and subscale scores of participants are also given. 
http://wjst.wu.ac.th

Table 4 Inter Subscale Correlation Matrix

\begin{tabular}{lll}
\hline Subscales & FOIAD & SI \\
\hline SI & $0.470^{* *}$ & - \\
LOCAH & $0.594^{* *}$ & $0.584^{* *}$
\end{tabular}

Note: FOIAD $=$ Fear of Infection and Death; SI = Social Isolation; LOCAH $=$ Loss of Control and Helplessness $* p<0.05 . * * p 0.01$.

Table 4 presents an inter subscale correlation matrix that shows positive relationships between 3 factors, suggesting the interrelatedness of components with overall CVAS.

Table 5 Correlations between IES-R and scores on CVAS overall and its subscales.

\begin{tabular}{ll}
\hline Scales & CIES-R \\
\hline FOIAD & $0.392^{* *}$ \\
SI & $0.418^{* *}$ \\
LOCAH & $0.436^{* *}$ \\
CVAS T & $0.476^{* *}$ \\
\hline
\end{tabular}

Note: IES-R = Impact of Event Scale-Revised; CVAS T = Corona Virus Anxiety Scale Total; FOIAD = Fear of Infection and Death; SI $=$ Social Isolation; LOCAH $=$ Loss of Control and Helplessness $* p<0.05$. $* * p<0.01$

Table 5 shows a positive and significant correlation between IES-R and subscale scores in the CVAS. The relationship between overall CVAS and IES-R is also positively significant.

\section{Discussion}

The purpose of the study, to develop and validate a scale to measure anxiety and related fears during an outbreak of COVID-19, emerged out of the fact that the psychological care of individuals exposed to COVID-19 infections is often ignored [27]. Exploratory factor analysis suggests 17-item CVAS is 3 dimensional with all items that emerged in factors, as expected. Three-factor solutions provided clarity and explained $57.46 \%$ variance. Item analysis showed positive, significant, and above 0.4 coefficient values for the item-total correlation in overall CVAS and its subscales.

Overall, for the CVAS, item-17 showed the peaked value of item-total correlation. Several previous studies have affirmed perpetuation of stigmatization, such as avoidance, differential attitudes, constricted social involvements, suspicion and fear, and disrespectful remarks during epidemic viral outbreaks $[28,29]$. Individuals refrained from interactions with Chinese people out of concern about getting Chinese infection during the SARS epidemics [30]. Inter subscale correlations suggested the relatedness of items with the overall construct. Percentile scores showing cutoff values for overall and subscales suggested high $\left(75^{\text {th }}\right.$ percentile), medium $\left(50^{\text {th }}\right.$ percentile), and low $\left(25^{\text {th }}\right.$ percentile) levels of anxiety among individuals (Table 3).

Adequate values of Cronbach's alpha reliabilities for overall and subscales suggested the CVAS is a reliable tool. SI showed the highest alpha value, which was followed by FOAID and LOCAH, showing that anxieties about social isolation are relatively pronounced concerning COVID-19. FOAID represents fear of infection to one's self, family members and loved ones, In FOAID, items \#2 \& 3 represented somewhat similar worries about the infection of family members and showed high values; a study carried out during times of viral epidemics shows that individuals show high levels of fears about the transmission of the virus to family members [31]. 
http://wjst.wu.ac.th

In SI, item 14, addressing the fear of social isolation, showed maximum value $(\mathrm{r}=0.61, p<0.01)$ (Table 2). Studies have pointed out that, during viral epidemics, anxiety stemming from lack of mobility, hampered daily schedule, constricted social and physical interactions producing monotony and feelings of being detached from the world [32-36], and inability to shop for essential needs and participate in routine works becomes a source of distress [37].

In LOCAH, items related to concern about the hike of prices of food and grocery items showed the highest value. Economic losses during epidemic viral outbreaks threatened the psychological states of individuals [38] and paucities of life-sustaining items like water, food, clothes, and housing creates irritability [39]. Individuals with the risk of COVID-19 infection reported psychological problems which include stress, depression, generalized anxiety, and insomnia [40]; such findings affirm experts' points of view about the significance of supplying psychological assistance along with medical interventions for more than half of the population infected by COVID-19 [41].

Positive significant correlation values of the IES-R with the CVAS overall and subscale scores demonstrate the construct validity of the scale. It is imperative to include other anxiety scales for further psychometric improvements of the CVAS, like the Anxiety Sensitivity Index, (ASI-3), the Short Health Anxiety Inventory (SHAI), and the Depression Anxiety Stress Scales (DASS-21) [42-44].

In conclusion, the outcomes of the present study suggest the CVAS is a reliable and valid tool. It is recommended to investigate further psychometric refinements in terms of reliabilities, validities, and cross-cultural studies, and allow the development and utilization of a CVAS-Thai version in future studies.

\section{References}

[1] NS Zhong, BJ Zheng, YM Li, Poon, ZH Xie, KH Chan, PH Li, SY Tan, Q Chang, JP Xie, XQ Liu, $\mathrm{J} \mathrm{Xu}, \mathrm{DX} \mathrm{Li}, \mathrm{KY}$ Yuen, Peiris and Y Guan. Epidemiology and cause of severe acute respiratory syndrome (SARS) in Guangdong, People's Republic of China, in February, 2003. Lancet 2003; 362, 1353-8.

[2] MN Al-Ahdal, AA Al-Qahtani and S Rubino. Coronavirus respiratory illness in Saudi Arabia. $J$. Infect. Dev. Ctries. 2012; 6, 692-4.

[3] E Mahase. China coronavirus: WHO declares international emergency as death toll exceeds 200. BMJ 2020; 368, m408.

[4] H Nishiura, SM Jung, NM Linton, R Kinoshita, Y Yang, K Hayashi, T Kobayashi, B Yuan and AR Akhmetzhanov. The extent of transmission of novel coronavirus in Wuhan, China, 2020. J. Clin. Med. 2020; 9, 330.

[5] S Perlman. Editorial: Another decade, another coronavirus. N. Engl. J. Med. 2020; 382, 760-2.

[6] YT Xiang. Timely mental health care for the 2019 novel coronavirus outbreak is urgently needed. Lancet Psychiatr. 2020, 7, 228-9.

[7] TB Liu, XY Chen, GD Miao, L Zhang, Q Zhang and T Cheung. Recommendations on diagnostic criteria and prevention of SARS-related mental disorders. J. Clin. Psychol. Med. 2003; 13, 188-91.

[8] R Maunder, J Hunter, L Vincent, J Bennett, N Peladeau, M Leszcz, J Sadavoy, LM Verhaeghe, R Steinberg and T Mazzulli. The immediate psychological and occupational impact of the 2003 SARS outbreak in a teaching hospital. Can. Med. Assoc. J. 2003; 168, 1245-51.

[9] RCW Hall and MJ Chapman. The 1995 Kikwit Ebola outbreak: Lessons hospitals and physicians can apply to future viral epidemics. Gen. Hosp. Psychiatr. 2008, 30, 446-52.

[10] GJ Rubin, HWW Potts and S Michie. The impact of communications about swine flu (influenza A H1N1v) on public responses to the outbreak: Results from 36 national telephone surveys in the UK. Health Tech. Assess 2010, 14, 183-266.

[11] TV Bortel. Psychosocial effects of an Ebola outbreak at individual, community and international levels. Bull. World Health Organ. 2016, 94, 210-4.

[12] A Patel and DB Jernigan. Initial public health response and interim clinical guidance for the 2019 novel coronavirus outbreak-United States, 31 December 2019 - 4 February 2020. MMWR Morb. Mortal. Wkly. Rep. 2020, 69, 140-6. 
http://wjst.wu.ac.th

[13] SA Lee. Coronavirus Anxiety Scale: A brief mental health screener for COVID-19 related anxiety. Death Stud. 2020; 44, 393-401.

[14] Government of Pakistan. Coronavirus in Pakistan, Available at: http://covid.gov.pk/stats/Pakistan, accessed June 2020.

[15] K Hamilton. The politics of fear: Médecins Sans Frontières and the West African Ebola epidemic. Emerg. Infect. Dis. 2017; 23, 1934.

[16] DK Kilgo, J Yoo and TJ Johnson. Spreading Ebola Panic: Newspaper and social media coverage of the 2014 Ebola Health Crisis. Health Commun. 2019; 34, 811-7.

[17] MS Sinha and WE Parmet. The Perils of Panic: Ebola, HIV, and the intersection of global health and law. Am. J. Law. Med. 2016; 42, 223-55.

[18] SM Ho, RS Kwong-Lo, CW Mak and JS Wong. Fear of severe acute respiratory syndrome (SARS) among health care workers. J. Consult. Clin. Psychol. 2005; 73, 344-9.

[19] J Wretman. Reflections on Probability vs Nonprobability Sampling. Official Statistics in Honour of Daniel Thorburn, 2010, p. 29-35.

[20] A Shorten and C Moorley. Selecting the sample. Evid. Based. Nurs. 2014; 17, 32-3.

[21] DS Weiss and CR Marmar. The Impact of Event Scale - Revised. In: JP Wilson and TM Keane (Eds.). Assessing Psychological Trauma and PTSD. Guilford Press, New York, 1997, p. 399-411.

[22] SM Ho, RS Kwong-Lo, CW Mak and JS Wong. Fear of severe acute respiratory syndrome (SARS) among health care workers. J. Consult. Clin. Psychol. 2005; 73, 344-9.

[23] EM Kean, K Kelsay, F Wamboldt and MZ Wamboldt. Posttraumatic stress in adolescents with asthma and their parents. J. Am. Acad. Child. Adolesc. Psychiatr. 2006; 45, 78-86.

[24] T Yonemoto, K Kamibeppu, T Ishii, S Iwata, Y Hagiwara and S Tatezaki. Psychosocial outcomes in long-term survivors of high-grade osteosarcoma: A Japanese single-center experience. Anticancer Res. 2009; 29, 4287-90.

[25] ML Gillies, J Barton and AD Gallo. Follow-up of young road accident victims. J. Trauma. Stress 2003; 16, 523-6.

[26] I Schäfer, C Barkmann, P Riedesser and M Schulte-Markwort. Posttraumatic syndromes in children andadolescents after road traffic accidents: A prospective cohort study. Psychopathology 2006; 39, 159-64.

[27] YT Xiang, Y Yang, W Li, L Zhang, Q Zhang, T Cheung and CH Ng. Timely mental health care for the 2019 novel coronavirus outbreak is urgently needed. Lancet Psychiatr. 2020; 7. 228-9.

[28] MA Cava, KE Fay, HJ Beanlands, EA McCay and R Wignall. The experience of quarantine for individuals affected by SARS in Toronto. Public Health Nurs. 2005; 22, 398-406.

[29] S Lee, LY Chan, AM Chau, KP Kwok and A Kleinman. The experience of SARS-related stigma at Amoy Gardens. Soc. Sci. Med. 2005; 61, 2038-46.

[30] R Keil and H Ali. Multiculturalism, racism and infectious disease in the global city: The experience of the 2003 SARS outbreak in Toronto. Topia 2006; 16, 10.

[31] Y Bai, CC Lin, CY Lin, JY Chen, CM Chue and P Chou. Survey of stress reactions among health care workers involved with the SARS outbreak. Psychiatr Serv. 2004; 55, 1055-7.

[32] RJ Blendon, JM Benson, CM DesRoches, E Raleigh and K Taylor-Clark. The public's response to severe acute respiratory syndrome in Toronto and the United States. Clin. Infect. Dis. 2004; 38, 925 31.

[33] A Braunack-Mayer, R Tooher, JE Collins, JM Street and H Marshall. Understanding the school community's response to school closures during the H1N1 2009 influenza pandemic. BMC Public Health 2013; 13, 344.

[34] DL Reynolds, JR Garay, SL Deamond, MK Moran, W Gold and R Styra. Understanding, compliance and psychological impact of the SARS quarantine experience. Epidemiol. Infect. 2008; 136, 997-1007.

[35] E Robertson, K Hershenfield, SL Grace and DE Stewart. The psychosocial effects of being quarantined following exposure to SARS: A qualitative study of Toronto health care workers. Can. J. Psychiatr. 2004; 49, 403-7. 
http://wjst.wu.ac.th

[36] Wilken JA, Pordell P, Goode B, et al. Knowledge, attitudes, and practices among members of households actively monitored or quarantined to prevent transmission of Ebola virus diseaseMargibi County, Liberia: February-March 2015. Prehosp. Disaster Med. 2017; 32, 673-8.

[37] L Hawryluck, WL Gold, S Robinson, S Pogorski, S Galea and R Styra. SARS control and psychological effects of quarantine, Toronto, Canada. Emerg. Infect. Dis. 2004; 10, 1206-12.

[38] M Mihashi, Y Otsubo, X Yinjuan, K Nagatomi, M Hoshiko and T Ishitake. Predictive factors of psychological disorder development during recovery following SARS outbreak. Health Psychol. 2009; 28, 91-100.

[39] MA Cava, KE Fay, HJ Beanlands, EA McCay and R Wignall. The experience of quarantine for individuals affected by SARS in Toronto. Public Health Nurs. 2005; 22, 398-406.

[40] S Liu, L Yang, C Zhang, YT Xiang, Z Liu, S Hu and B Zhang. Online mental health services in China during the COVID-19 outbreak. Lancet Psychiatr. 2020; 7, e17-e18.

[41] J Axelrod. CBS News, March 2, 2020: Coronavirus may infect up to $70 \%$ of world's population, expertwarns. https://www.cbsnews.com/news/coronavirus-infection-outbreak-worldwide-virusexpert-warning-today-2020-03-02, accessed June 2020.

[42] S Taylor, MJ Zvolensky, BJ Cox, B Deacon, RG Heimberg, DR Ledley, JS Abramowitz, RM Holaway, B Sandin, SH Stewart, M Coles, W Eng, ES Daly, WA Arrindell, M Bouvard and SJ Cardenas. Robust dimensions of anxiety sensitivity: Development and initial validation of the anxiety sensitivity index-3. Psychol. Assess. 2007; 19, 176-88.

[43] PM Salkovskis, KA Rimes, HM Warwick and DM Clark. The health anxiety inventory: Development and validation of scales for the measurement of health anxiety and hypochondriasis. Psychol. Med. 2002; 32, 843-53.

[44] M Antony, PJ Bieling, BJ Cox, MW Enns, RP Swinson. Psychometric properties of the 42-item and 21-item versions of the Depression Anxiety Stress Scales in clinical groups and community a sample. Psychol. Assess. 1998; 10, 176-81. 